\title{
The use of clozapine in adolescents: A case report
}

\begin{abstract}
Aili Hanim Hashim, MBBS, MPM (Malaya)
Subash Kumar Pillai, MBBS, MPM (Malaya)

Amer Siddiq Amer Nordin, MB ChB, MPM (Malaya)

Manveen Kaur, MBBS, MPM (Malaya)

Department of Psychological Medicine, Faculty

of Medicine, University of Malaya, Kuala Lumpur,

Malaysia
\end{abstract}

We report on a young adolescent diagnosed with early-onset schizophrenia and subsequently treated with clozapine. Clozapine is often used as the last line of treatment for patients with schizophrenia, even in the paediatric population. This report highlights the usefulness and challenges of using clozapine in adolescents with schizophrenia.

Clozapine was the first atypical neuroleptic to be developed, and has been used since the 1960s. It is well known as the treatment of 'last resort'. 1.2 In clinical practice there is often reluctance to switch individuals to this medication because of its side-effect profile, despite its proven efficacy even in treatment-resistant schizophrenia.

The adolescent and child psychiatry unit at the University of Malaya Medical Centre, Kuala Lumpur, has a section that specifically caters for children diagnosed with early-onset psychosis. The unit is currently treating 3 adolescents with clozapine (the number is increasing). One of these cases will be described in this report.

\section{Case report}

A 15-year-old Chinese girl was brought to the unit by her parents in 2008. She had been treated by a private psychiatrist for over a year, and had been receiving an atypical antipsychotic. Her parents felt that she had done fairly well initially, but her condition worsened. She was suspicious of her classmates and felt that they were constantly making comments about her, and also complained that she could not trust her friends. Her parents were worried that she would act on these suspicions. She was unable to concentrate on her lessons and her grades deteriorated. At home the situation was no better - she told her parents that she hated them, even accused her father of raping her, and was angry with her mother for not believing this. She was irritable and had a lot to say when spoken to. She also complained that her eyelids were not wide enough and that she needed to go for an operation to widen them. She wore a lot of make-up and thick clothing. She also had sleep problems, staying up at night, reading magazines and watching television until the early hours of the morning.

During the mental state examination the patient denied experiencing any auditory hallucinations, but was noted to be speaking to herself.

Even with good compliance with medication the patient's symptoms worsened. It was decided that the best option was to switch to another atypical antipsychotic. However, after 21/2 months, although she was sleeping better, she became more aggressive and her parents were afraid of her frequent outbursts. It was decided to try another atypical antipsychotic, but despite increasing the dose of the medication and allowing sufficient time for it to have an effect, no improvement was noted. It was then decided to try clozapine.

The patient had had no previous medical illnesses of note. There was no history of substance use, and no significant family history of mental illness. A computed tomography scan of the brain and the results of relevant routine blood tests were normal.

After a week on clozapine, the patient seemed calmer and began to socialise appropriately with her family. She remained in the ward for another week and was eventually discharged on $150 \mathrm{mg}$ clozapine at night. During subsequent follow-up she was found to be calm and had no psychotic features. She was eventually able to start going to school again. Her parents were happy with her improvement, and her blood parameters remained within normal limits.

\section{Discussion}

Early-onset schizophrenia is defined as onset before the age of 18 years, with very early onset before the age of 13 years. ${ }^{4}$ It is often a terrifying and debilitating condition, and costly for the child and the family. Reports have suggested that the outcome is not generally favourable and that it is a progressively deteriorating developmental disorder, with up to $25 \%$ having a full remission with a good prognosis, another $25 \%$ showing partial remission, and up to $50 \%$ becoming chronic. ${ }^{46}$ Individuals receiving treatment for a first episode of schizophrenia often demonstrate a lasting response to antipsychotic medications, though a subgroup are left with significant persisting psychotic symptoms. ${ }^{79}$ The focus during recent years has been on improving understanding of the illness and ultimately more effective intervention.

Reports have demonstrated the efficacy of clozapine..$^{10,1}$ Unfortunately the therapeutic benefits may be accompanied by 
severe adverse effects in children. ${ }^{3,11,12}$ The most serious side-effect is bone marrow suppression and agranulocytosis, which has delayed the acceptance of clozapine into clinical practice. ${ }^{13}$

However, failure to treat children who do not respond to routine treatment because of a fear of side-effects is not justifiable, as the risk of not treating schizophrenia is more serious than the adverse effects of treatment. Furthermore, a delay in treatment is often associated with poor results, as the longer the duration of untreated psychosis the worse the condition becomes, with functional outcome declining sharply. ${ }^{7.14}$ The persistent negative as well as positive symptoms are destructive to a child's development, to progress at school and to family and peer relationships, as was demonstrated in our case. The suicide rate in patients with childhood-onset schizophrenia has also been noted to be higher than in non-schizophrenics. Early treatment therefore has the potential to reduce the secondary impacts of this serious mental illness. ${ }^{5}$ In our case the onset of frequent episodes of aggression, which significantly affected the child's functioning, as well as the imminent potential harm to others indicated a need for immediate pharmacological intervention. Clearly the symptoms were not responding to the antipsychotics used.

Clozapine has value in the salvage of patients considered resistant to treatment, even in the paediatric population. ${ }^{10,15}$ It is the only drug licensed for the treatment of schizophrenia in individuals as young as 16 years who are unresponsive to or intolerant of conventional medication. ${ }^{16}$ Treatment-resistant patients are those who fail to respond to trials of two typical antipsychotics, or in this age of newer atypical antipsychotic agents who fail to experience a substantial reduction in psychopathology with at least three different antipsychotic agents. ${ }^{3,17}$

Although clozapine has the potential to cause severe side-effects, there is increasing evidence to advocate its use in the early treatment of first-episode patients whose psychosis does not remit with other second-generation antipsychotics.' It has been suggested that clozapine should be positioned as a second-line treatment for first-episode schizophrenics who fail one trial of a second-generation antipsychotic. .118, $^{19}$

The most frequent side-effects observed are drowsiness, drooling, nonspecific excitatory changes on the electro-encephalogram (EEG), transient psychomotor agitation and eosinophilia. ${ }^{12,20}$ General guidelines for using clozapine in children are the same as for adults, but since there is a higher rate of side-effects in children, clozapine must be used with extra caution in the paediatric population, and close monitoring for adverse events is essential. Monitoring of the white blood cell count is similar to that in adults, i.e. blood counts should be done weekly for the first 6 months of treatment and every second week thereafter. It is prudent to do a baseline test, and to include a baseline EEG. It is also recommended that lower doses of antipsychotics than in adults be used to achieve a therapeutic response. 'Start low, go slow, taper slow' dosing strategies are especially important when atypical antipsychotic agents are tried on adolescents. ${ }^{3}$ The longterm outcome in treatment-resistant children seems to be predicted best by the improvement seen at 6 weeks, by which time most progress will have occurred. 10,21 This was noted in our case.

Bipolar disorder typically presents with affective and at times psychotic symptoms. Mania in adolescents can therefore present with psychotic symptoms, i.e. delusions, hallucinations and thought disorder. ${ }^{22}$ Our patient demonstrated prominent delusions of reference and persecution, and although she denied hearing any voices, she was seen talking to herself. There were no overt manic or depressive symptoms, although she did display irritability. The diagnosis of schizophrenia rather than a psychotic mood disorder was therefore made. However, longitudinal assessment is needed to ensure accuracy of diagnosis in all such cases. $^{23}$

As our child mental health services increase, we are likely to see more children with early-onset treatment-resistant schizophrenia. It is hoped that this report will add to the current body of knowledge and encourage clinicians in this part of the world to use clozapine for the benefit of our child patients. More than 15 studies have demonstrated the antipsychotic efficacy of clozapine in childhood and adolescent schizophrenia. ${ }^{24}$ The main advantages of clozapine treatment in this age group in comparison with typical antipsychotics are: (i) good antipsychotic efficacy during an acute schizophrenic episode; (ii) better improvement in chronic cases with a high load of negative symptoms; and (iii) markedly fewer extrapyramidal adverse effects, and therefore fairly good tolerability.

\section{References}

1. Agid $\mathrm{O}$, Kapur $\mathrm{S}$, Arenovich $\mathrm{T}$, et al. Delayed-onset hypothesis of antipsychotic action: a hypothesis tested and rejected. Arch Gen Psychiatry 2003;60(12):228235

2. Agid $O$, Remington G, Kapur, S, Arenovich T, Zipursky RB. Early use of clozapine for poorly responding first-episode psychosis. J Psychopharmacol 2007:27(4):369-373.

3. Findling RL, Frazier JA, Gerbino-Rosen G, et al. Is there a role for clozapine in the treatment of children and adolescents? J Am Acad Child Adolesc Psychiatry 2007:46:423-428.

4. Kumra S, Frazier JA, Jacobsen LK, et al. Childhood-onset schizophrenia: A double blind clozapine-haloperidol comparison. Arch Gen Psychiatry 1996;53:1 090-1097.

5. Lieberman J, Jody D, Geisler S, et al. Time course and biologic correlates of treatment response in first-episode schizophrenia. Arch Gen Psychiatry 1993;50(5):369-376.

6. Remschmidt H, Hennighausen K, Clement HW, Heiser P, Schulz E. Atypical neuroleptics in child and adolescent psychiatry. Eur Child Adolesc Psychiatry 2000;9: 1/9-1/19

7. Cirulli G. Clozapine prescribing in adolescent psychiatry: survey of prescribing practice in in-patient units. Psychiatr Bull 2005;29:377-380

8. Davis JM, Schaffer $C B$, Killian GA, et al. Important issues in the drug treatment of schizophrenia. Schizophr Bull 1980;6(1):70-87

9. Remschmidt H, Martin M, Fleischhaker C, et al. Forty-two-years later: the outcome of childhood-onset schizophrenia. J Neural Transm 2007; 1 14:505-512.

10. Kapur S, Arenovich T, Agid O, et al. Evidence for onset of antipsychotic effects within the first 24 hours of treatment. Am J Psychiatry 2005; 162(5):939-946.

1 1. Robinson DG, Woerner MG, Alvir JM, et al. Predictors of treatment response from a first episode of schizophrenia or schizoaffective disorder. Am J Psychiatry 1999; 156(4):544-549

12. Sporn A, Gogtay N, Bobb A, et al. Clozapine treatment of childhood-onset schizophrenia: Evaluation of effectiveness, adverse effects, and long-erm outcome. J Am Acad Child Adolesc Psychiatry 2007;46(10): 1349-1356. 
13. Pappadopulos E, Macintyre JC, Crismon ML, et al. Treatment recommendations for the use of antipsychotics for aggressive youth (TRAAY). Part II. J Am Acad Child Adolesc Psychiatry 2003;42(2):145-161

14. Harrigan, SM, Mcgorry PD, Krstev H. Does treatment delay in firsteepisode psychosis really matter? Psychol Med 2003;33(1):97-1 10

15. Frazier JA, Gordon CT, McKenna K, Lenane MC, Jih D, Rapoport JL. An open trial of clozapine in 11 adolescents with childhood-onset schizophrenia. J Am Acad Child Adolesc Psychiatry 1994;33:658-663.

16. US Food and Drug Administration. Patient information sheet, clozapine. Rockville, Md: FDA, 2004 - 2007. www.drugs.com/pro/clozapine. html laccessed 13 September 20101.

17. American Psychiatric Association. Practice guideline for the treatment of patients with schizophrenia. Am J Psychiatry 1997; 154(4, suppl): 1-63.

18. Kane J, Honigfeld G, Singer J, Meltzer H, and the Clozaril Study Group. Clozapine for the treatment resistant schizophrenic. Arch Gen Psychiatry 1988;45:789-796.

19. McClellan J, Werry J. Practice parameters for the assessment and treatment of children and adolescents with schizophrenia. J Am Acad Child Adolesc Psychiatry 1994;33:616-635
20. Turetz M, Mozes T, Toren P, et al. An open trial of clozapine in neuroleptic-resistant childhood-onset schizophrenia. Br J Psychiatry 1997;170:507-510.

21. Shaw P, Sporn A, Gogtay N, et al. Childhood-onset schizophrenia: A double-blind, randomized clozapine-olanzapine comparison. Arch Gen Psychiatry 2006;63:721730.

22. Carlson GA. Child and adolescent mania: diagnostic considerations. J Child Psychol Psychiatry 1990;31:331-342.

23. Werry JS, McClellan J, Andrews L, Ham M. Clinical features and outcome of child and adolescent schizophrenia. Schizophr Bull 1994;20:619-630.

24. Scahill L, Kimberly AL. Atypical neuroleptics in children and adolescents. J Child Adolesc Psychiatr Nurs 1998; 1 1 (1):38-43.

25. Waddington JL, Scully PJ, O'Callaghan E. The new antipsychotics and their potential for early intervention in schizophrenia. Schizophr Res 1997;28:207-222. 